\section{Category}

Metal-Catalyzed Asymmetric

Synthesis and

Stereoselective

Reactions

\section{Key words}

\section{rhodium}

biaryl ligands

axial chirality

J. ZHENG, S.-L. YOU* (SHANGHAI INSTITUTE OF ORGANIC CHEMISTRY, P. R. OF CHINA) Construction of Axial Chirality by Rhodium-Catalyzed Asymmetric Dehydrogenative Heck Coupling of Biaryl Compounds with Alkenes

Angew. Chem. Int. Ed. 2014, 53, 13244-13247.

\title{
Enantioselective Rhodium-Catalyzed Synthesis of Axially Chiral Biaryls
}<smiles></smiles>

Selected examples:

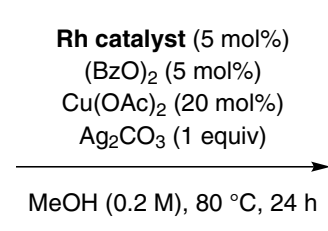<smiles></smiles>

up to $84 \%$ ee up to $97 \%$ yield $0.1 \mathrm{mmol}$ scale 23 examples

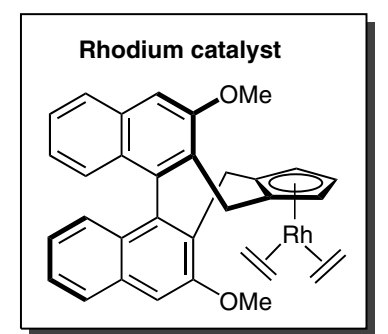

Significance: Several bioactive molecules contain an axially chiral biaryl subunit. Although several methods exist for their synthesis, the use of direct $\mathrm{C}-\mathrm{H}$ functionalization is less well studied. The authors present a rhodium-catalyzed dehydrogenative Heck coupling to produce axially chiral biaryls using the Cramer complex.
Comment: The substrate scope showed variability in the aza biaryl starting material and the olefin coupling partner. The products were shown to be competent in rhodium-catalyzed 1,4-additions to cyclohexenone with phenylboronic acid, producing the adduct in up to $77 \%$ yield and with $68 \%$ ee.

SYNFACTS Contributors: Mark Lautens, Zafar Qureshi 